\title{
A multiple-scale assessment of long-term aspen persistence and elevational range shifts in the Colorado Front Range
}

\author{
Mario Bretfeld, ${ }^{1,3}$ Scott B. Franklin, ${ }^{1}$ and Robert K. Peet ${ }^{2}$ \\ ${ }^{1}$ School of Biological Sciences, University of Northern Colorado, Greeley, Colorado, 80639 USA \\ ${ }^{2}$ College of Arts and Sciences, University of North Carolina, Chapel Hill, North Carolina 27559 USA
}

\begin{abstract}
Aspen forests and woodlands are some of the most species-rich forest communities in the northern hemisphere. Changing climate, altered disturbance regimes, land use, and increased herbivore pressure threaten these forests both in Eurasia and North America. In addition, rapid mortality dubbed "Sudden Aspen Decline" is a concern for aspen's long-term presence in the western United States, especially Colorado and Utah. Yet it is still unclear whether aspen is persistent or declining at the landscape scale. We assessed aspen persistence at different spatial scales in the Colorado Front Range by resampling 89 plots containing aspen from among 305 vegetation plots sampled by Robert Peet during 1972-1973. We hypothesized that aspen density and basal area had decreased at the landscape scale, with notable variability in change depending on the forest community type, and that this overall decrease has been more pronounced at lower elevations. We also assessed elevational range shifts of the major species in these forests. Aspen were no longer present in 22 of the 89 plots and aspen density for stems less than $2.5 \mathrm{~cm}$ diameter at breast height (DBH) had declined significantly overall, although density of medium $(2.5-10 \mathrm{~cm} \mathrm{DBH})$ and large $(>10 \mathrm{~cm}$ DBH) trees, as well as basal area, had not changed significantly. A comparison between montane $(<2700 \mathrm{~m}$ elevation) and subalpine (2700-3500 m elevation) plots revealed that the decrease was more pronounced at higher elevations and was mostly the result of substantial decreases of stems in the eleven plots that were part of Peet's aspen-dominated "Populus tremuloides series." In these plots, aspen basal area decreased significantly whereas basal area of Abies bifolia, Picea engelmannii, Pinus contorta, and Pseudotsuga menziesii increased substantially. Upslope shifts were observed for most species, especially on northeast facing slopes, suggesting climate-related responses. In summary, aspen have been resilient in mixed forests and may be beneficiaries of recent bark beetle epidemics, but have decreased and been subject to successional transitions in previously aspen-dominated stands. Our results confirm the importance of regionspecific, multiple-scale assessments of species persistence to make best management recommendations.
\end{abstract}

Key words: climate change; elevation shift; forest dynamics; long-term; montane; mountain pine beetle; plant community; Populus tremuloides; subalpine; succession.

\section{INTRODUCTION}

Evidence overwhelmingly suggests that global climate change is occurring at an unprecedented rate (IPCC 2013), resulting in widespread alterations to both abiotic and biotic factors that are driving composition of forest ecosystems. Researchers worldwide are assessing the ramifications of the changing climate on vegetation, including elevation range shifts (e.g., Allen and Breshears 1998, Kelly and Goulden 2008, Lenoir et al. 2008, Parolo and Rossi 2008, Kopp and Cleland 2014), latitudinal range shifts (Woodall et al. 2009, Evans et al. 2015, Wei et al. 2015), species dominance shifts (Harte and Shaw 1995,

Manuscript received 29 June 2015; revised 5 December 2015; accepted 15 December 2015. Corresponding Editor: J. B. Yavitt.

[3E-mail: m.bretfeld@gmail.com
Jagerbrand et al. 2009), assembly of novel communities (Williams and Jackson 2007), and potential loss of biodiversity (Thuiller et al. 2005). Assuming similar sampling procedures and locations, long-established vegetation plots provide unique opportunities to directly and accurately assess long-term changes in forest composition (Crawford et al. 1998, Smith and Smith 2005, Kopecký and Macek 2015), as well as species diversity and distributions (Damschen et al. 2010, Kopp and Cleland 2014). We resampled a subset of 89 plots from among 305 0.1-ha vegetation plots first sampled by Robert Peet during 1972-1973 in Rocky Mountain National Park, Colorado, USA, to assess changes in woody species composition at different spatial scales and shifts in elevation ranges after 40 years in forest plots originally containing quaking aspen (Populus tremuloides). 
Together with European aspen (Populus tremula), quaking aspen span a circumboreal distribution and are of high conservation concern across the majority of their ranges (Kouki et al. 2004, Edenius and Ericsson 2007, Kuhn et al. 2011). In North America, quaking aspen is the most widely distributed deciduous tree species, spanning from northern Alaska/Canada to central New Mexico (Little 1971). Almost 75\% of western aspen occur in Colorado and Utah (Bartos 2001). Considered to be a keystone species in subalpine and boreal forests of North America (Bartos 2001, Buck and St. Clair 2012), forests dominated by aspen provide a variety of crucial ecosystem services, including soil enrichment, watershed protection, wildlife habitat, economic products, landscape diversity, recreational opportunities, and an atmospheric $\mathrm{CO}_{2}$ sink (St. Clair et al. 2010). Species richness, nutrient cycling, and herbaceous biomass are generally higher under aspen than in co-occurring conifer-dominated habitats, justifying the interest in monitoring and protecting these communities (Chong et al. 2001, Stam et al. 2008, Buck and St. Clair 2012). Within the upper montane and subalpine elevation zones of the Colorado Front Range, aspen is the only major deciduous tree species and can serve as a prime indicator of the impacts of climate change on forest growth (Rehfeldt et al. 2009). From 1953 to 2008 , the upper montane and subalpine elevation zones of the Colorado Front Range exhibited significant increases in annual mean temperatures of $0.17^{\circ}$ and $0.20^{\circ} \mathrm{C}$ per decade, respectively (McGuire et al. 2012). The effects of these changes on aspen forests have yet to be directly assessed.

Establishment and survival of aspen is regulated by several factors, including disturbances such as fire, herbivore pressure, and climatic events (e.g., drought). As a result of warmer and drier spring and summer conditions, frequency and severity of forest fires have increased since the mid-1980s in the western United States (Westerling et al. 2006, Littell et al. 2009); however during most of the 20th century, fire occurrence in montane Ponderosa pine (Pinus ponderosa) forests in the northern Colorado Front Range was considerably below historic fire frequencies (Veblen et al. 2000). The similarly low occurrence of fire in the subalpine zone during the same period is believed to be within the historical range of variability during the past 400 years (Sibold et al. 2006); however, since both sexual and asexual (i.e., clonal or vegetative reproduction) regeneration of aspen are highly dependent on disturbances (Mitton and Grant 1996), low fire frequencies inevitably have a negative effect on aspen regeneration.

Although sexual reproduction may be more prevalent than previously thought (Long and Mock 2012), especially following severe disturbances and in more mesic locations (Kay 1993, Romme et al. 2005, Fairweather et al. 2014, Krasnow and Stephens 2015), vegetative reproduction remains the dominant mode of regeneration in aspen's southernmost distribution (Rogers et al. 2014). Initiation of vegetative (i.e., ramet or sucker) growth depends on several factors, including genetics, time of disturbance, pre-disturbance stand conditions, and nutrient and water supply (Frey et al. 2003). Suckering increases significantly following conifer removal (Jones et al. 2005), but can be suppressed by extensive browsing (Baker et al. 1997, Suzuki et al. 1999, Zeigenfuss et al. 2008).

Hunting in Colorado by early settlers resulted in the statewide extirpation of important predatory species, including wolves and grizzly bears. Although elk were also hunted to extirpation in some areas, they were reintroduced into the Rocky Mountain National Park region in 1913. The population increased rapidly due to the absence of large predators and has resulted in evident effects on aspen and willow populations in the park (Baker et al. 1997), mainly in form of localized suppression of regeneration, especially in heavily utilized elk (Cervus elaphus) winter ranges of lower elevations (Suzuki et al. 1999, Zeigenfuss et al. 2008). In 1968, a natural regulation policy was implemented consisting of hunting in adjacent areas outside the park boundaries to reduce herd size inside the park (Baker et al. 1997). Optimum management strategies are still being debated and more research is required to understand the complex interactions between aspen, elk, and management policies (Seager et al. 2013).

Researchers have suggested since the 1940s that aspen stands are declining in the western United States (Packard 1942, Krebill 1972) due mainly to the aforementioned reasons. More recently, the hastened loss of overstory trees due to Sudden Aspen Decline (SAD) suggests drought and resulting xylem cavitation as a factor (Worrall et al. 2008, 2013, Rehfeldt et al. 2009, Michaelian et al. 2011, Anderegg 2012, Anderegg et al. 2013, 2015). Research by Fairweather et al. (2008) in northern Arizona showed a decrease in drought-related mortality of aspen along an elevational gradient, with mortality rates of $95 \%$ below 7500 feet $(2286 \mathrm{~m}), 61 \%$ between 7500-8500 feet (2286-2590 m), and only $16 \%$ above 8500 feet $(2590 \mathrm{~m})$, suggesting an uphill shift of aspen's lower elevation range limit. In the Colorado Front Range, increasing average spring and summer temperatures are a function of both significantly increasing maximum temperatures in the montane zone and significantly increasing minimum temperatures in the subalpine zone since 1953 (McGuire et al. 2012). Subsequent reduced snowpack and earlier, accelerated snowmelt may also impact timing and intensity of herbivore pressure (Brodie et al. 2012). While it is unclear whether aspen have migrated in the Colorado Front Range, shifts in plant species elevational ranges have been reported in studies across the globe (e.g., Lenoir et al. 2008, Kopp and Cleland 2014, Wei et al. 2015).

Most studies of aspen persistence in the western United States report population declines (Packard 1942, Romme et al. 1995, Baker et al. 1997, Bartos and Campbell 1998, Ripple and Larsen 2000, Gallant et al. 2003, Di Orio et al. 2005, Smith and Smith 2005, Kashian et al. 2007, Rehfeldt et al. 2009), although others suggest 
aspen abundance has increased or has been persistent (Crawford et al. 1998, Suzuki et al. 1999, Barnett and Stohlgren 2001, Hessl and Graumlich 2002, Manier and Laven 2002, Elliott and Baker 2004, Kulakowski et al. 2004, 2006, Moore and Huffman 2004, Kaye et al. 2005, Romme et al. 2005, Zier and Baker 2006, Kurzel et al. 2007, Sankey 2008, 2012, Zeigenfuss et al. 2008). Recent work strongly suggests aspen decline is both spatially and temporally variable and depends on site characteristics, disturbance, succession to conifer forests, extreme climatic events (drought and anomalous cool, moist years), and herbivory (St. Clair et al. 2010, Sankey 2012, Rogers et al. 2013). Despite this variability, most of the observed decline in aspen over the past decade was documented in "montane seral aspen communities" (sensu Rogers et al. 2014), the dominant type of aspen communities in the Colorado Front Range.

Studies of aspen populations and regeneration success in Rocky Mountain National Park and adjacent forests have been mostly inconclusive, with results indicating decreasing or persisting populations (Packard 1942, Baker et al. 1997, Suzuki et al. 1999, Kaye et al. 2005, Kashian et al. 2007, Zeigenfuss et al. 2008). These studies have utilized a variety of techniques to assess population dynamics, such as dendrochronology (Kaye et al. 2005), regeneration success and age distribution (Packard 1942, Baker et al. 1997, Suzuki et al. 1999, Kashian et al. 2007), and genetic variation (Zeigenfuss et al. 2008). However, none of these studies compared current structure and composition of aspen forests to a previously sampled vegetation data set and overall inconclusive findings suggest the need for an assessment at multiple spatial scales. In addition, it is unclear how the recent bark beetle epidemic (predominantly mountain pine beetle; Dendroctonus ponderosae) affects aspen regeneration (Pelz and Smith 2013). Eruptive bark beetle outbreaks often result in a substantial change in species composition and a highly altered fuels complex (Lynch et al. 2007, Jenkins et al. 2008, 2012, Collins et al. 2012), considerably altering fire behavior in affected sites (Jenkins et al. 2008). Loss of pine trees from the bark beetle epidemic increases light to the forest floor and decreases competition, both factors that favor aspen growth and suckering (Shepperd et al. 2006, Pelz and Smith 2013). A modeling approach by Shaw (2004) suggests that mountain pine beetle outbreaks may result in pure aspen stands. Collins et al. (2012) also predict an increase in aspen density in stands affected by mountain pine beetle, especially followed by salvage logging. However, Klutsch et al. (2009) found that although aspen has the capacity to take advantage of openings in the canopy by sprouting from the parent root system, there were no significant differences in sucker density 4-7 years post beetle disturbance in north-central Colorado between infested and uninfested forests. Correspondingly, a recent study in central Colorado shows that sucker density was not significantly higher in beetle-affected forests (Bretfeld et al. 2015).
The objective of this study was to assess elevation shifts and composition changes in forest communities containing aspen during a 40-year period in the Colorado Front Range at three different spatial scales: landscape wide, elevation zone, and forest community type. Specifically, we hypothesized that (1) aspen basal area and density have decreased over the past 40 years at the landscape scale due to reduced fire frequency and increasingly dry and warm weather, (2) within this overall decrease, aspen change is variable depending on the local forest community type, and that (3) the extent of aspen decline is more evident at lower elevations due to increased browsing pressure in elk winter ranges and similar shifts in elevation range limits observed across the globe.

\section{Methods}

\section{Previous data collection}

During the interval 1972-1973, Peet (1981) sampled 305 forest plots, spanning the range of composition within the eastern slope of the northern Colorado Front Range from the foothills to the alpine, within or near Rocky Mountain National Park. The sampling method was a modified version of that used by Whittaker (1960). Plots typically were $20 \times 50 \mathrm{~m}(0.1 \mathrm{ha})$ with 25 contiguous $0.5 \times 2 \mathrm{~m}$ subplots located along the center line, in which detailed understory data (frequency and cover) were collected. Additional species that occurred elsewhere in the $20 \times 50 \mathrm{~m}$ plot were recorded as present without an estimate of overall cover. Species and diameter at breast height $(\mathrm{DBH}$; measured at $1.37 \mathrm{~m}$ height) were recorded by $2.5 \mathrm{~cm}$ classes for all trees in the 0.1 -ha plot. In addition, woody stems not reaching breast height were tallied in height classes of $50-100 \mathrm{~cm}$ and $100-137 \mathrm{~cm}$.

Plant communities were delimited using a hybrid of indirect and direct gradient analysis (Whittaker 1967). The final presentation used elevation (from topographic maps and altimeter readings) and topographic-moisture (derived from records of aspect and slope, and subjective estimates of site conditions) as the two primary axes for representing community variation (Peet 1981). Based on these gradients, Peet identified eight vegetation "series" and 29 community types (Peet 1981).

\section{Resample data collection}

Of Peet's original 305 plots, only those containing aspen at any quantity in any of the recorded strata were selected to be resampled. Locations of the resulting 95 plots (11 aspen dominated, 84 containing aspen) were transferred from Peet's original topographic maps into a GPS unit (Garmin Montana 600 Olathe, Kansas USA). After approaching the marked location, abiotic factors (slope, aspect, rock cover) and biotic factors (woody species composition) as recorded by Peet were compared to assure accurate plot location. If abiotic factors at the 
intended site did not match Peet's data, the surrounding area was searched in a $150 \mathrm{~m}$ radius, based on Peet's original plot location accuracy assessment (Peet 1981), for matching topography and site characteristics. If no aspen were present on site, the same radius was searched for presence of aspen and, if any were found, the plot was moved to include aspen, as long as there were no changes in site abiotic factors, ensuring a conservative estimate of potential aspen loss over the past 40 years. In some justifiable cases, the search radius from Peet's original location was deliberately increased: plot 153 was originally marked outside the topographic map with its approximate location determined on the basis of slope position, aspect, and slope; plot 178 was located on the riverbank of North Fork Big Thomson River, which may have changed over the years: its approximate location was based on biotic factors. A total of 89 plots were resampled while six plots were not sampled as a result of changes in landownership, land use, or uncertainty of exact plot location. While we acknowledge that it is unlikely that exact locations were resampled, due to lack of permanent markers, we feel confident that our sampled plots are within Peet's original sampling accuracy of $150 \mathrm{~m}$. The validity of our comparison is further supported by Kopecký and Macek (2015), who have shown that resurveys of historical plots are robust to plot location uncertainty.

Each plot was sampled following the Carolina Vegetation Survey (CVS) protocol (Peet et al. 1998) at the highest sampling depth (level 5). The CVS protocol was developed to maintain maximum comparability with other widely used methods (Peet et al. 1998), including the Whitaker method that was originally utilized by Peet. The CVS protocol is a modular approach, with $10 \times 10 \mathrm{~m}$ sampling units (modules). Given adequate site homogeneity, 10 such modules were established along a 50-m center line (five on each side) resulting in a $20 \times 50 \mathrm{~m}$ (0.1-ha) plot. The center line was laid out perpendicular to the slope. Species and counts were recorded for all live woody individuals in the 0.1-ha plot in 11 size classes (0-0.9, 1-2.49, 2.5-4.9, 5-9.9, 10-14.9, 15-19.9, 20-24.9, 25-29.9, 30-34.9, 35-39.9, $\geq 40 \mathrm{~cm} \mathrm{DBH).} \mathrm{For} \mathrm{trees} \geq 40 \mathrm{~cm}$ $\mathrm{DBH}$, measurements were recorded in $1 \mathrm{~cm}$ increments, since small differences in diameter at large sizes produce large differences in basal area. To identify bark beetles as mortality agents, dead conifers were inspected for typical pitch tubes and exit holes. Site characteristics recorded include aspect, slope, substrate depth, and percent cover for organic debris, rock, and water. Each plot was GPS marked and pictures were taken at the plot origin (at $0 \mathrm{~m}$ of center line).

\section{Data analysis and comparison}

Taxonomy of species follows Ackerfield (2013). Density data were normalized to number of stems per hectare in order to allow for adequate comparison to Peet's data. Although occasionally reaching breast height $(1.37 \mathrm{~m})$, several species were not considered part of the overstory; specifically Acer glabrum, Amelanchier pumila, Cornus stolonifera, Jamesia americana, Lonicera involucrata, Physocarpus monogynus, Prunus virginiana, Ribes cereum, $R$. inerme, $R$. lacustre, Rosa blanda, Salix spp., and Viburnum edule were excluded from the comparison and were instead included in a separate understory vegetation analysis (Bretfeld 2014). Peet did not include individuals below $0.5 "(1.27 \mathrm{~cm}) \mathrm{DBH}$ in his basal area calculations. We recalculated basal area of all species for Peet's data in the same manner as we did for the recent data to allow for more precise comparison between the data sets.

Density and basal area comparisons were made for the most prominent species: Abies bifolia (synonym: Abies lasiocarpa; ABBI), Picea engelmannii (PIEN), Pinus contorta (PICO), Pinus flexilis (PIFL), Pinus ponderosa (PIPO), Populus tremuloides (POTR), and Pseudotsuga menziesii (PSME). For the less abundant species Alnus incana (ALIN), Betula occidentalis (BEOC), Juniperus scopulorum (JUSC), Picea pungens (PIPU), Populus angustifolia (POAN), and Sorbus scopulina (SOSC), analysis was limited to descriptive statistics unless an adequate sample size was present. For density analyses, data were categorized in three size classes based on DBH: small $(<2.5 \mathrm{~cm})$, medium $(2.5-10 \mathrm{~cm})$, and large $(>10 \mathrm{~cm})$.

Malanson et al. (2011) recommend that topographic influences and site-specific responses nested within regional patterns must be considered when assessing vegetation. We agree and assessed changes at three different scales: all plots combined (landscape scale), per elevation zone (montane and subalpine, 2100-2700 m and 2700-3500 m, respectively, based on Hess and Alexander [1986]) and per series (to test for forest-typespecific differences), the latter based on Peet's classification (Peet 1981). For series represented by too few samples, analysis was limited to descriptive statistics (Table 1). All data were tested for normality using the Shapiro-Wilk test. Since data were nonnormal, further analyses were performed using nonparametric tests. Significance of change was calculated from differences in density and basal area between previously sampled and recent data sets using the Wilcoxon signed rank test $\left(H_{0}\right.$ : difference is $0 ; \alpha=0.05)$. To adjust for multiple tests, the Holm-Bonferroni correction was applied. Significant results based on both adjusted and non-adjusted alphas were interpreted to include statistically conservative as well as potential ecologically significant results and false acceptances of null hypotheses (Pike 2011). All statistical tests were performed in R (Version 3.0.0) or PC-ORD (Version 6.08). Spatial analyses, such as elevation derivations, were performed in ArcMap (Version 10.0; Esri, Redlands, California, USA).

\section{Elevational shifts}

Of the 89 resampled plots, 37 were in the montane and 52 in the subalpine elevation zone (Hess and Alexander 
TABLE 1. Number of resampled plots per elevation zone, series, and community type.

\begin{tabular}{|c|c|c|c|c|}
\hline Series & Community & All & Montane† & Subalpinet \\
\hline Pinus ponderosa woodland (A)§ & Mesic montane woodland & 2 & 2 & 0 \\
\hline \multirow[t]{3}{*}{ P. ponderosa - Pseudotsuga forest (B) } & Foothill $P$. ponderosa - Pseudotsuga forest & 5 & 5 & 0 \\
\hline & Foothill ravine forest & 2 & 2 & 0 \\
\hline & Xeric Pseudotsuga forest & 2 & 0 & 2 \\
\hline \multirow[t]{4}{*}{ Mesic montane forest (C) } & Mesic montane forest & 4 & 4 & 0 \\
\hline & Mixed mesic forest & 8 & 6 & 2 \\
\hline & Montane ravine forest & 7 & 7 & 0 \\
\hline & Wet montane forest & 3 & 2 & 1 \\
\hline \multirow[t]{5}{*}{ Pinus contorta forest (D) } & Mesic $P$. contorta $-P$ seudotsuga forest & 6 & 6 & 0 \\
\hline & Mesic $P$. contorta - Abies, Picea forest & 7 & 1 & 6 \\
\hline & Pinus contorta forest & 12 & 0 & 12 \\
\hline & Xeric $P$. contorta - Abies, Picea forest & 6 & 0 & 6 \\
\hline & Xeric $P$. contorta - Pseudotsuga forest & 4 & 0 & 4 \\
\hline Picea, Abies forest $(E)^{\S}$ & Mesic Picea, Abies forest & 1 & 0 & 1 \\
\hline \multirow[t]{3}{*}{ Pinus flexilis forest (F) } & Montane $P$. flexilis forest & 7 & 0 & 7 \\
\hline & P. flexilis-Picea, Abies forest & 1 & 0 & 1 \\
\hline & Subalpine $P$. flexilis forest & 1 & 0 & 1 \\
\hline Populus tremuloides forest $(\mathrm{H})$ & P. tremuloides forest & 11 & 2 & 9 \\
\hline Total & & 89 & 37 & 52 \\
\hline
\end{tabular}

†Upper montane zone elevation range: $2100-2700 \mathrm{~m}$.

tSubalpine zone elevation range: $2700-3500 \mathrm{~m}$.

$\S$ Analysis limited to descriptive statistics.

1986; Table 1). To assess potential species migration, we compared median elevations weighted by species basal area and sapling/seedling density (i.e., all trees $<10 \mathrm{~cm}$ $\mathrm{DBH}$ ) between data sets. Using small trees as a proxy for changes in addition to basal area allows for detection of short-term responses to climate that are likely lagged in mature trees (Woodall et al. 2009). Comparisons were grouped based on aspect (northeast [315-134 ${ }^{\circ}$ ] vs. southwest $\left[135-314^{\circ}\right]$ ), representing cold-moist and warm-dry local climates, respectively.

\section{RESULTS}

\section{Changes at the landscape scale}

Comparison of cumulative numbers of stems at the landscape scale show a decrease in the smallest stratum for all species except Alnus incana (Fig. 1A). Considerable increases in both medium and large tree strata occurred only in Abies bifolia and Picea engelmannii. Most evident is the extreme decrease of Populus tremuloides within all strata, as well as clear decreases in Pinus contorta and Pinus flexilis. Cumulative basal area changes indicate decreases in Pinus contorta, Pinus flexilis, Populus angustifolia, Populus tremuloides, and Pseudotsuga menziesii, whereas Picea engelmannii, Picea pungens, and Pinus ponderosa all increased in basal area (Fig. 1B). These shifts resulted in an overall loss of $4.69 \mathrm{~m}^{2} / \mathrm{ha}$ of basal area.

Statistically significant changes at the landscape scale occurred mostly in the smallest stratum, with seven species showing a significant decrease in density of small trees (Table 2). Picea engelmannii density in the large tree stratum and basal area increased, whereas Pinus flexilis basal area decreased significantly (Table 2, Appendix S1). Although cumulative changes were highest in Populus tremuloides, only the decrease in the smallest stratum was statistically significant at the landscape scale (Fig. 2A). Aspen were not found in any stratum in 22 plots, representing $24.7 \%$ of the 89 plots where it was previously present. A Multi-Response Permutation Procedure (MRPP) analysis showed no significant differences between plots where aspen was lost vs. plots where aspen were still present, based on aspect, slope, elevation, ground cover, soil depth, and vegetation cover $(P=0.63, \delta$ [weighted mean within-group distance $=0.056)$. As expected, plots that lost aspen exhibited low aspen abundance initially; average basal area in plots that lost aspen was $0.34 \mathrm{~m}^{2} / \mathrm{ha}$ compared to $6.95 \mathrm{~m}^{2} /$ ha for plots in which aspen were still present.

\section{Changes at the elevation-zone scale}

Significant decreases in stem density occurred for five species in the smallest stratum in the montane zone (Table 2). Pinus contorta significantly decreased both in large tree density and basal area in the montane zone (Table 2). In the subalpine zone, five species decreased significantly in density in the smallest stratum, and Pinus ponderosa decreased in the large tree stratum, while Abies bifolia, Picea engelmannii, and Pseudotsuga menziesii increased in the medium tree stratum, and Abies bifolia in the large tree stratum (Table 2). Only Abies bifolia exhibited a significant increase in basal area in the subalpine zone. 

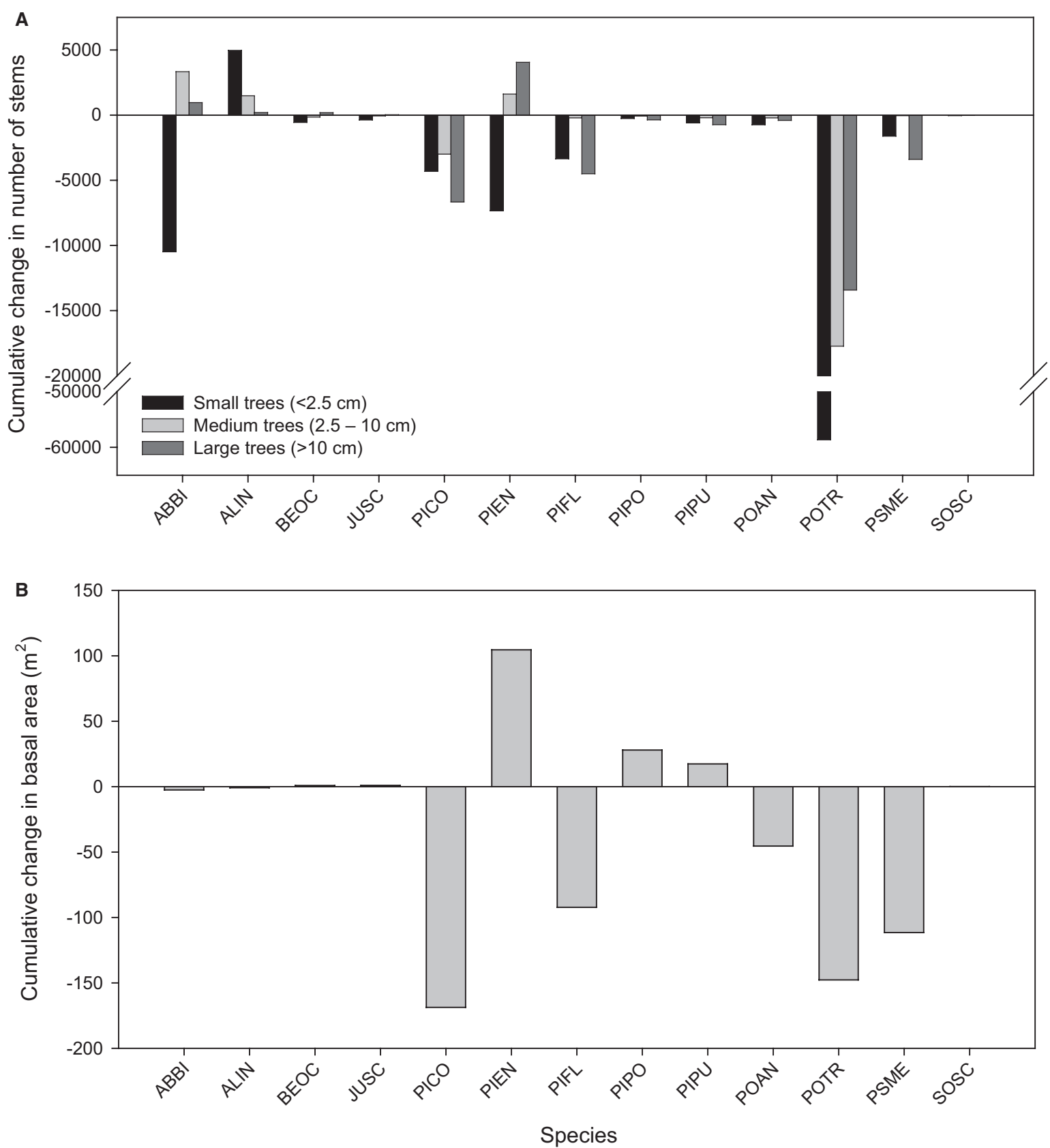

FIG. 1. (A) Changes in cumulative number of stems for all 13 tree species at the landscape scale (89 plots). (B) Changes in cumulative basal area for all 13 tree species at the landscape scale ( 89 plots). Species codes: Abies bifolia (synonym: Abies lasiocarpa; ABBI), Picea engelmannii (PIEN), Pinus contorta (PICO), Pinus flexilis (PIFL), Pinus ponderosa (PIPO), Populus tremuloides (POTR), Pseudotsuga menziesii (PSME), Alnus incana (ALIN), Betula occidentalis (BEOC), Juniperus scopulorum (JUSC), Picea pungens (PIPU), Populus angustifolia (POAN), Sorbus scopulina (SOSC).

\section{Changes at the series scale}

The largest change occurred in the Pinus contorta forest (D) series, with five species decreasing in density in the smallest stratum and Pinus ponderosa decreasing in both density in the medium tree stratum and total basal area (Table 2). Mesic montane forests (C) exhibited the second largest change, with a significant decrease in density of Abies bifolia, Juniperus scopulorum, and Picea engelmannii in the smallest stratum, as well as a significant decrease in Pinus contorta in the large tree stratum. The Pinus ponderosa-Pseudotsuga series (B) was largely unchanged, with only Pseudotsuga menziesii density decreasing significantly in the smallest 
TABLE 2. Significant $(P<0.05)$ increases and decreases in density per stratum and basal area $(\mathrm{BA})$ at landscape, elevation zone, and forest series scales.

\begin{tabular}{|c|c|c|c|c|c|c|c|c|}
\hline \multirow[b]{2}{*}{ Scale } & \multicolumn{4}{|c|}{ Increasing } & \multicolumn{4}{|c|}{ Decreasing } \\
\hline & $\mathrm{S}$ & M & $\mathrm{L}$ & BA & $\mathrm{S}$ & M & $\mathrm{L}$ & BA \\
\hline Landscape & & & PIEN & PIEN & $\begin{array}{l}\text { ABBI, } \\
\text { JUSC, } \\
\text { PICO, } \\
\text { PIEN, } \\
\text { PIFL, } \\
\text { POTR, } \\
\text { PSME }\end{array}$ & & & PIFL \\
\hline Montane $\dagger$ & & & & & $\begin{array}{l}\text { ABBI, } \\
\text { JUSC, } \\
\text { PIEN, } \\
\text { PIFL, } \\
\text { PSME }\end{array}$ & & $\mathrm{PICO}$ & $\mathrm{PICO}$ \\
\hline Subalpine: & & $\begin{array}{l}\text { ABBI, } \\
\text { PIEN, } \\
\text { PSME }\end{array}$ & PIEN & PIEN & $\begin{array}{l}\text { ABBI, } \\
\text { PICO, } \\
\text { PIEN, } \\
\text { PIFL, } \\
\text { POTR }\end{array}$ & & PIPO & \\
\hline $\begin{array}{l}\text { Pinus ponderosa-Pseudotsuga } \\
\text { forest (B) }\end{array}$ & & & & & PSME & & & \\
\hline Mesic montane forest $(\mathrm{C})$ & & & & & $\begin{array}{l}\text { ABBI } \\
\text { JUSC, } \\
\text { PIEN }\end{array}$ & & PICO & \\
\hline Pinus contorta forest (D) & & & & & $\begin{array}{l}\text { ABBI, } \\
\text { PICO, } \\
\text { PIEN, } \\
\text { PIFL, } \\
\text { POTR }\end{array}$ & PIPO & PIPO & \\
\hline Pinus flexilis forest (F) & & ABBI & ABBI & ABBI & $\begin{array}{l}\text { PIFL, } \\
\text { POTR }\end{array}$ & & & \\
\hline Populus tremuloides forest $(\mathrm{H})$ & & & & & POTR & & & POTR \\
\hline
\end{tabular}

Notes: Tree strata are small (S), $<2.5 \mathrm{~cm} \mathrm{DBH}$; medium (M), $2.5-10 \mathrm{~cm} \mathrm{DBH}$; and large (L), $>10 \mathrm{~cm}$ DBH. Significant changes after application of Holm-Bonferroni correction are indicated by boldface type. Species codes are Abies bifolia (synonym: Abies lasiocarpa; ABBI), Picea engelmannii (PIEN), Pinus contorta (PICO), Pinus flexilis (PIFL), Pinus ponderosa (PIPO), Populus tremuloides (POTR), Pseudotsuga menziesii (PSME), and Juniperus scopulorum (JUSC). Pinus ponderosa woodland (A) and Picea, Abies forests (E) were excluded from statistical analyses due to low sample sizes.

$\dagger$ Upper montane zone elevation range: $2100-2700 \mathrm{~m}$

$\$$ Subalpine zone elevation range: $2700-3500 \mathrm{~m}$.

stratum. Data from Pinus flexilis forests (F) indicate a shift toward Abies bifolia, with significant increases in density in the medium and large tree strata, as well as total basal area, while Pinus flexilis and Populus tremuloides density decreased in the smallest stratum.

The Populus tremuloides series $(\mathrm{H})$ exhibited a significant decrease in density of Populus tremuloides in the smallest stratum and in total basal area (Table 2, Fig. 3A and D). Although not significant at the $\alpha=0.05$ level, densities of Populus tremuloides in both the medium$(P=0.058, V$ the sum of the positive-signed ranks] $=6)$ and large-tree $(P=0.053, V=11)$ strata decreased, whereas densities of Picea engelmannii (medium and large tree stratum; $P=0.057, V=15$ and 0.051 , $V=26$ respectively), Pinus contorta (large tree stratum; $P=0.059, V=46.5)$, and basal area of Pseudotsuga menziesii $(P=0.059, V=15)$ and Picea engelmannii $(P=0.08, V=45)$ all increased (Table 2, Fig. 3). These changes were reflected in the proportion of basal area for each species (Fig. 4). The aspen stem density decrease was most pronounced in the Populus tremuloides $(\mathrm{H})$ series (Fig. 5). Changes in the Pinus ponderosa woodland (A) and Picea, Abies forest (E) series were not statistically analyzed due to low sample sizes.

\section{Elevational shifts}

Upslope shifts based on basal area are evident in Abies bifolia, Pinus contorta, and Picea engelmannii, while Populus tremuloides shifted downslope (Table 3, Fig. 6A). All species except Populus tremuloides and Pinus flexilis exhibited upslope shifts based on seedling/sapling densities (Fig. 6 B). Shifts of Abies bifolia, Pinus contorta, and Picea engelmannii are notably more pronounced on northeast facing slopes compared to southwest facing slopes (Fig. 6C-F). Among all plots, upslope shifts occurred at a rate of $28.2 \mathrm{~m}$ and $35.9 \mathrm{~m}$ per decade based on seedling/sapling density and basal area, respectively, and downslope shifts occurred 

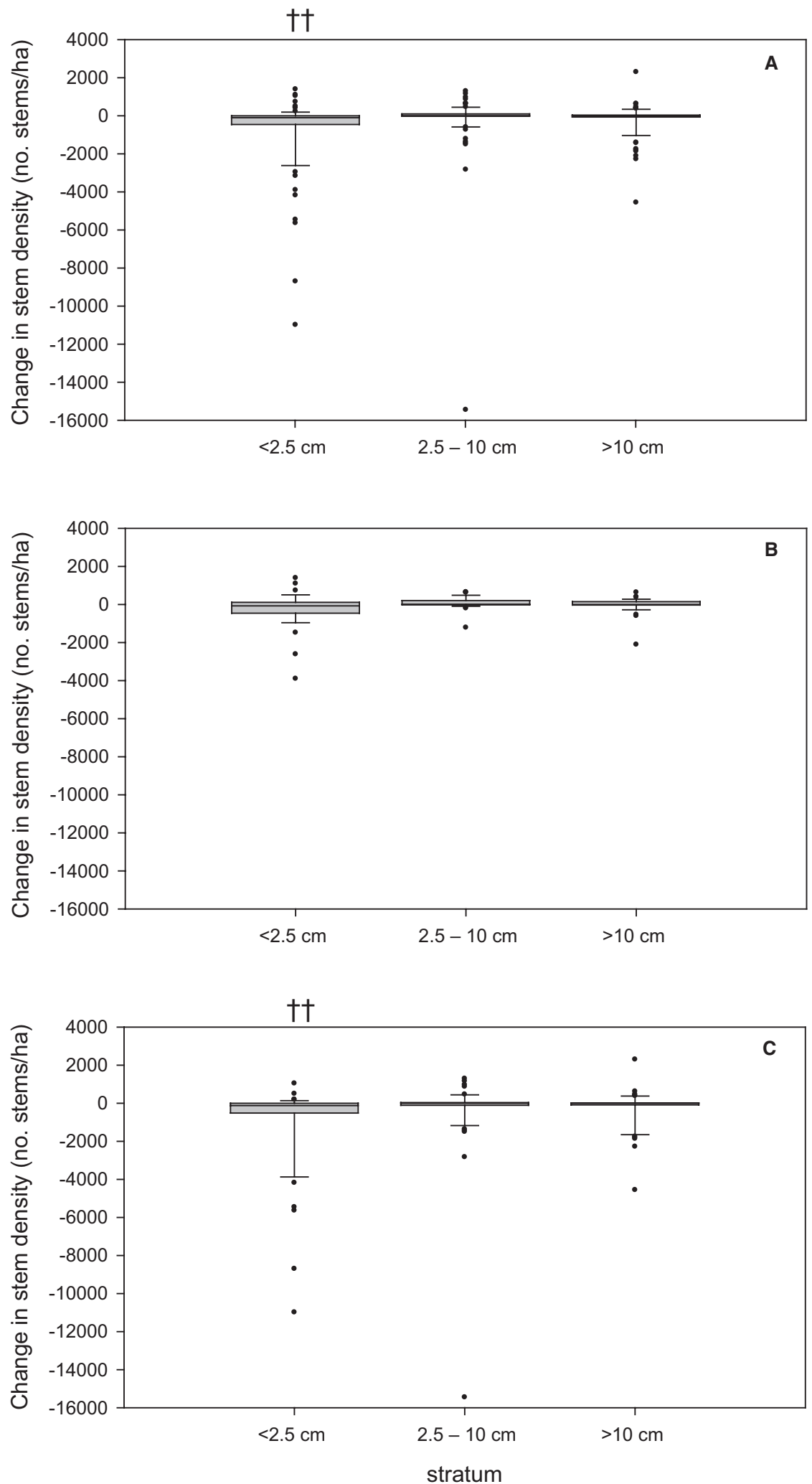

FIG. 2. Changes in stem density per hectare for Populus tremuloides at the (A) landscape scale (89 plots) and in the (B) montane (32 plots) and (C) subalpine ( 57 plots) zones for the three size strata. Significant changes (decrease) after Holm-Bonferroni adjustment are indicated by $\uparrow$. Box plots show median (horizontal line), 25th and 75th percentiles (box edges), 10th and 90th percentiles (whiskers), and outlying points. 

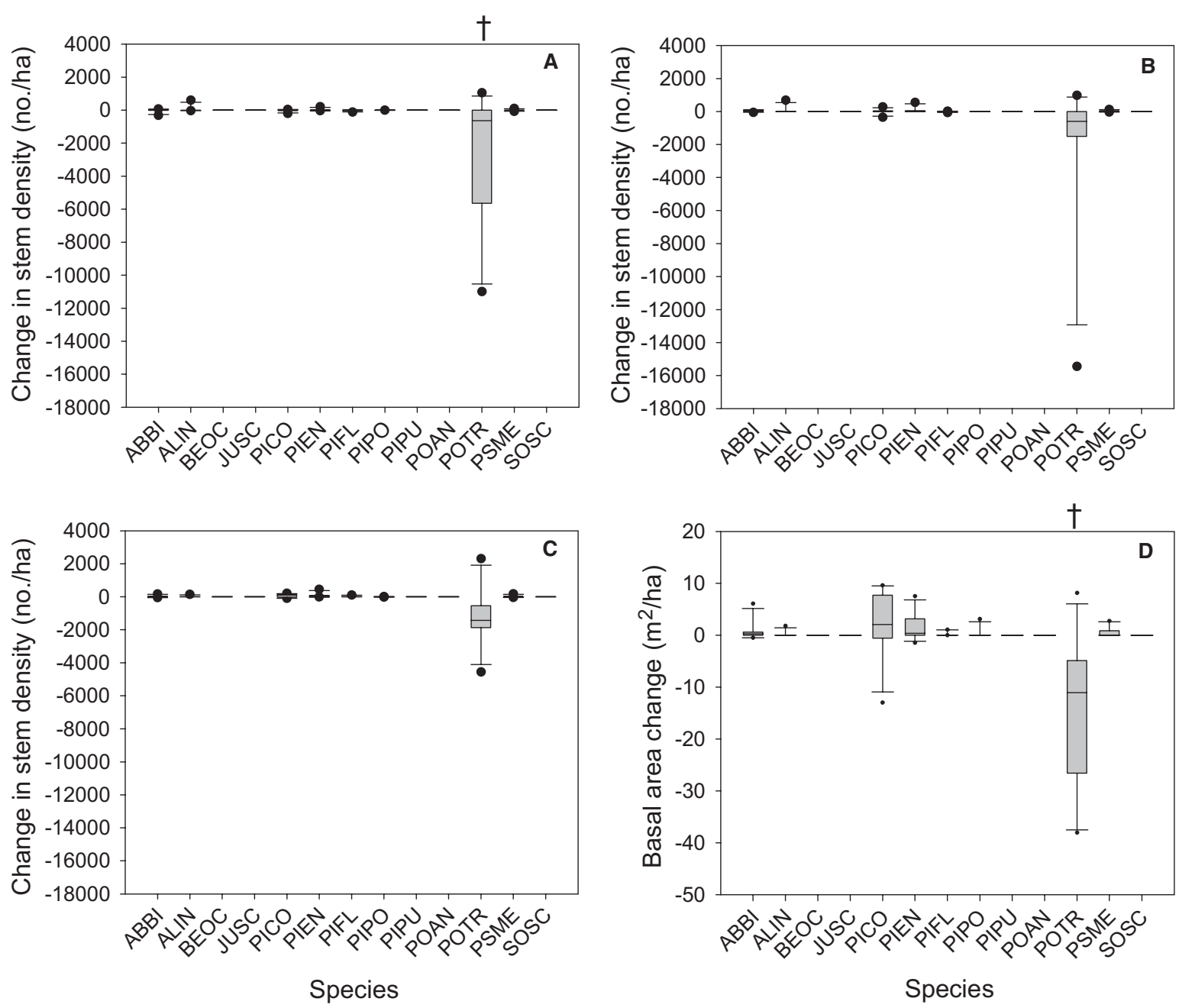

FIG. 3. Changes in (A, B, C) stem density and (D) basal area for all 13 species in the Populus tremuloides series (11 plots) for (A) small $(<2.5 \mathrm{~cm})$, (B) medium $(2.5-10 \mathrm{~cm})$, and $(C)$ large $(>2.5 \mathrm{~cm})$ trees. Significant $(\alpha=0.05$, no adjustment $)$ changes $($ decrease) are indicated by $\uparrow$. Species codes are as in Fig. 1.

at a rate of $-15.6 \mathrm{~m}$ and $-4.4 \mathrm{~m}$ per decade, based on seedling/sapling density and basal area, respectively.

\section{DisCUSSION}

To assess long-term change in montane and subalpine forests containing aspen, we resampled 89 plots originally established in 1972-1973 (Peet 1981) and analyzed the data at three different spatial scales. Our results show a landscape-wide decrease in total basal area among all species $(-15.86 \%)$, and a general decrease in density, especially in the smallest size stratum, potentially indicative of age-related self-thinning (Westoby 1984). Aplet et al. (1988) showed that spruce-fir forests in north-central Colorado exhibit their highest basal area at the age of 175 years, with overall basal area decreasing by almost one-third by the age of 375 years. Precise fire history data based on dendrochronological analysis was available for 43 of the 89 plots (Buechling and Baker 2004, Sibold et al. 2006). The average stand age of these plots was $\sim 208$ years since last fire, with the oldest stand being 477 (1536) and the most recently burned stand 57 years old (excluding plot 86 that burned in the 2012 Fern Lake Fire), suggesting that most plots fell within the age at which overall basal area naturally declines. Furthermore, a recent mountain pine beetle epidemic has likely contributed to the observed decreases in Pinus contorta basal area, which account for $29.64 \%$ of the total forest basal area loss (Fig. 1B). The only statistically significant decrease in basal area at the landscape scale was observed for Pinus flexilis, a species of conservation concern. Pinus flexilis is believed to have been declining during the past several decades in Colorado due to fire suppression, as the species requires disturbances for recruitment, except on the most xeric sites and, more recently, due to the spread of white pine blister rust (Cronartium ribicola) and the mountain pine beetle epidemic (Rebertus et al. 1991, Kearns and Jacobi 2007, Coop and Schoettle 2009). Our 


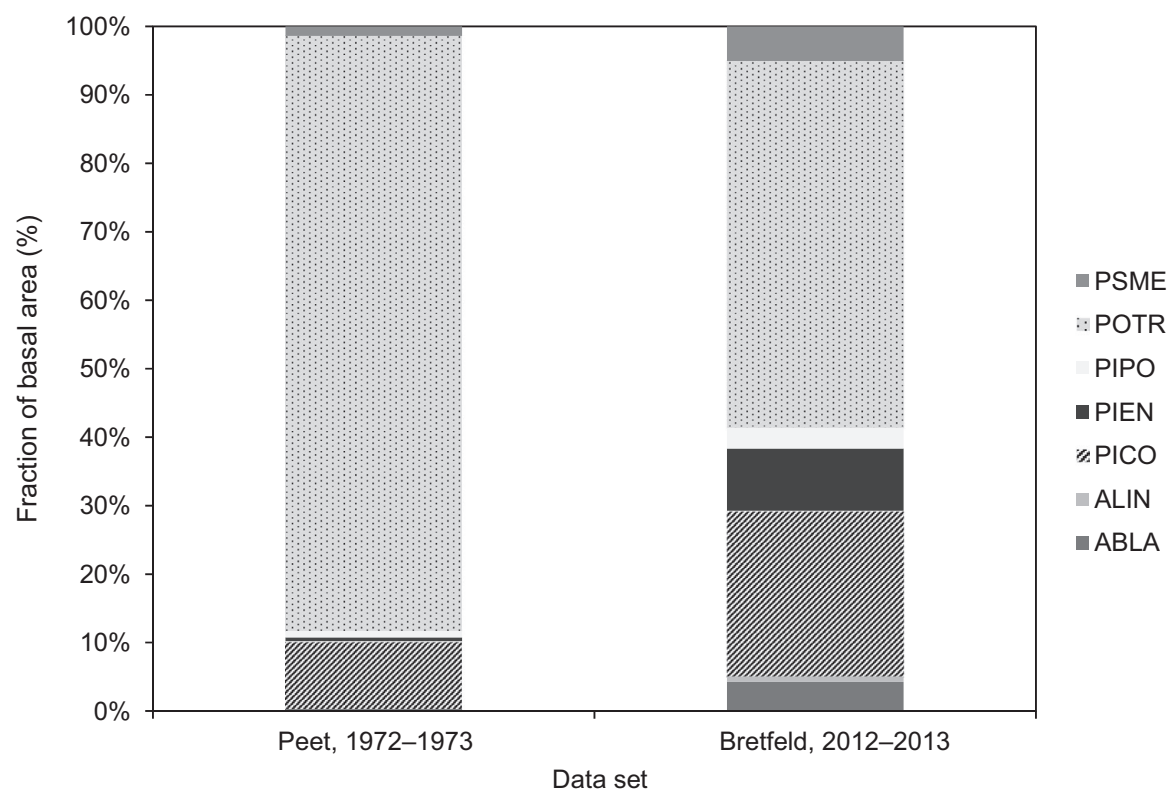

FIG. 4. Comparison of basal area distribution for 11 plots in the Populus tremuloides series. Cumulative basal area for all 11 plots was $323.4 \mathrm{~m}^{2}(1972-1973)$ and $228.3 \mathrm{~m}^{2}$ (2012-2013). Species that were not present in the series were not plotted. Species codes are as in Fig. 1.

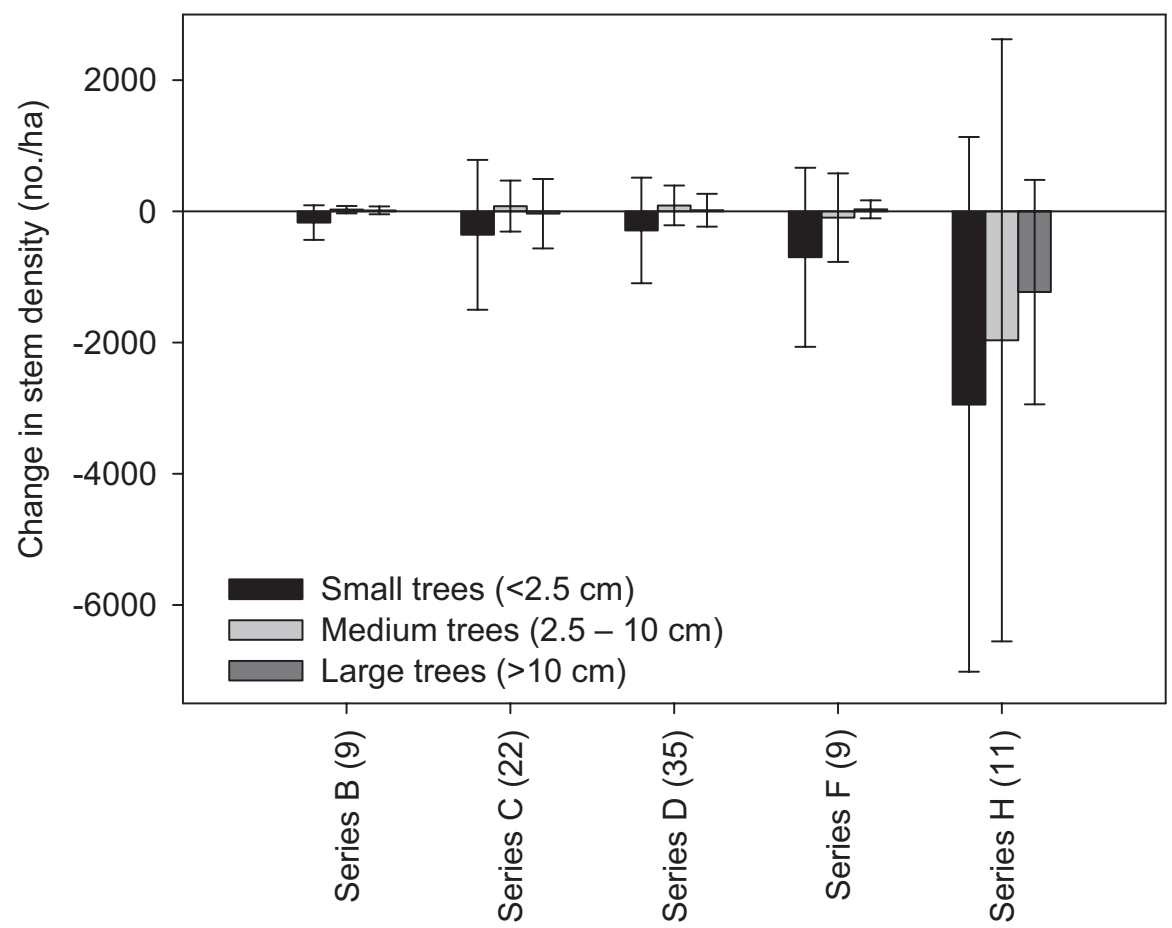

FIG. 5. Average changes in Populus tremuloides densities at the series scale: Pinus ponderosa-Pseudotsuga forest (Series B), Mesic montane forest (C), Pinus contorta forest (D), Pinus flexilis forest (F), Populus tremuloides forest (H). Numbers in parenthesis on the $\mathrm{x}$-axis represent sample sizes. Error bars represent one standard deviation.

data support the notion that limber pines are decreasing in Colorado at the landscape scale. However, additional data on regeneration of this species should be collected as the present study was limited to sites containing aspen and is not representative of the entire range of limber pine forest communities. 
TABLE 3. Elevation range shifts ( $\mathrm{m} /$ decade) based on comparison between medians weighted by basal area and small tree density

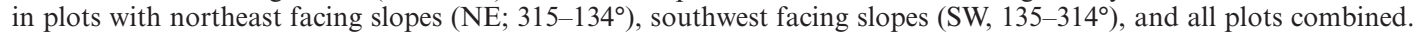

\begin{tabular}{|c|c|c|c|c|c|c|}
\hline \multirow[b]{2}{*}{ Species } & \multicolumn{3}{|c|}{ Small tree density } & \multicolumn{3}{|c|}{ Basal area } \\
\hline & $\mathrm{NE}$ & SW & All & $\mathrm{NE}$ & SW & All \\
\hline Abies bifolia & 42.7 & 0.0 & 42.7 & 17.2 & 0.0 & 42.7 \\
\hline Pinus contorta & 22.8 & -1.2 & 0.0 & 9.5 & 21.2 & 30.7 \\
\hline Picea engelmannii & 30.0 & -4.5 & 12.0 & 47.5 & 3.7 & 34.3 \\
\hline Pinus flexilis & -8.5 & 0.0 & -6.2 & 2.3 & 0.0 & 0.0 \\
\hline Pinus ponderosa & -53.9 & 43.2 & 43.2 & 5.9 & 0.0 & 0.0 \\
\hline Populus tremuloides & -49.2 & -18.5 & -25.0 & -4.7 & 12.2 & -8.5 \\
\hline Pseudotsuga menziesii & 6.0 & 155.8 & 14.5 & 5.5 & -35.5 & -0.3 \\
\hline
\end{tabular}

\section{Aspen population}

Although aspen was no longer present in 22 of the 89 sampled plots, our data only partially support our first hypothesis that aspen have decreased in density and basal area during the past 40 years in the Colorado Front Range. While the decrease in density at the landscape scale seems extensive and is statistically significant for the smallest stratum, most of this decline occurred in the eleven plots of the Populus tremuloides $(\mathrm{H})$ series, accounting for $55.1 \%, 94.9 \%$, and $94.0 \%$ of total decline in small, medium, and large tree strata, respectively. Total basal area in the Populus tremuloides $(\mathrm{H})$ series decreased by $29.4 \%$, all due to a significant $57.0 \%$ reduction of aspen basal area. While considerable aspen stems have been lost in this series in all strata, likely due to canopy closing and natural self-thinning as aspen stands mature (Lieffers et al. 2002), increases in Picea engelmannii, Pinus contorta, and Pseudotsuga menziesii were observed (Fig. 4). An accurate fire history record was available for seven of the 11 plots in that series (Buechling and Baker 2004, Sibold et al. 2006). Average stand age was 124 years. The most recent fire has occurred in plot 182 (date of fire: 1952), the only plot of the Populus tremuloides $(\mathrm{H})$ series where aspen density and basal area had increased despite increases in coniferous species. All 11 plots of the Populus tremuloides $(\mathrm{H})$ series fall into the "seral montane" aspen community type (Harniss and Harper 1982, Rogers et al. 2014), as they show a clear trajectory toward increasing coniferous dominance as part of typical successional sequence (Peet 1981, Bartos 2001, Lieffers et al. 2002, Frey et al. 2004). While pure aspen stands on the western slope in Colorado have been reported to be stable based on resampled plots over 20 years, the same study found significant increases in conifer basal area in mixed stands, similar to our study (Smith and Smith 2005). A resampling effort of 19 plots established in 1964 near Crested Butte, Colorado, showed that although decreases in aspen density and basal area were found in aspen dominated habitats, conifer encroachment was minor despite initial conifer presence (Coop et al. 2014).

None of the here resampled plots exhibited stable, pure aspen stands. However, in contrast to the strong decrease of aspen in the Populus tremuloides $(\mathrm{H})$ series, other series exhibited little change in aspen density and several series even exhibited increases in the medium and large tree strata, most notably in the Pinus contorta (D) series (Fig. 5), supporting hypothesis two that aspen change is variable based on forest community type. Canopy openings and reduced competition caused by extensive beetle-induced mortality of conifers likely resulted in favorable conditions for increased survival of mature aspen stems. While some studies suggest that aspen have the potential to take advantage of beetle-induced conifer die-off through increased suckering and delayed conifer encroachment 10-15 years after outbreak (Hadley and Veblen 1993, DeRose and Long 2010), others found no significant differences between infested and non-infested stands 4-7 years after outbreak (Klutsch et al. 2009), and thus aspen response is not yet fully understood (Pelz and Smith 2013). A recent study showed that regeneration of aspen in Fraser Valley, Colorado, was not significantly different between plots with high and low beetle-induced conifer mortality 4-10 years after outbreak; however, dendrochronological data showed increased vigor in mature aspen (Bretfeld et al. 2015), supporting findings in this study that despite decreases in the smallest stratum, mature aspen are more resilient to succession in forests heavily affected by bark beetles (Fig. 5).

The third hypothesis, that a decrease in aspen is more pronounced at lower elevations, was not supported by data from this study. Instead, the most substantial decrease in density in the smallest stratum occurred in the subalpine zone (Fig. 2C). While it should be noted that nine of the 11 plots of the Populus tremuloides $(\mathrm{H})$ series were located in the subalpine and only two in the montane elevation zone, excluding this series from the analysis yielded similar results, with a significant decrease in small tree density only in the subalpine zone $(P<0.001$, $V=143)$, whereas no significance was detected in the montane zone $(P=0.071, V=204)$. Differences in stand age and resulting canopy closure are unlikely the driving factors for this difference since the average years since the last fire were similar, dating to 1804 and 1805 for the montane and subalpine zones, respectively (Buechling and Baker 2004, Sibold et al. 2006). 

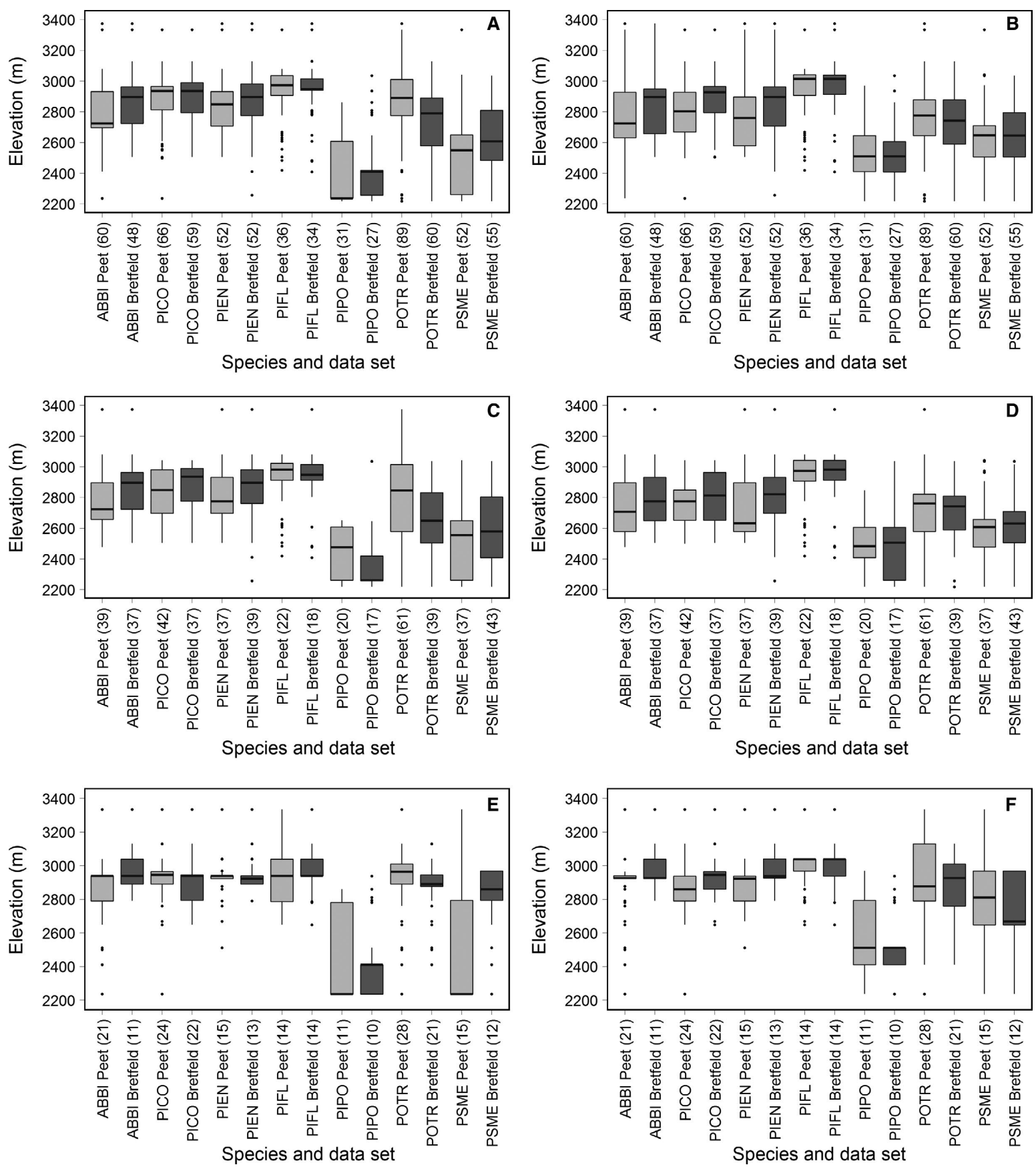

FIG. 6. Elevation range comparison between the two data sets. Comparisons are shown for sapling/seedling density (A) in all plots, (C) on northeast facing slopes, and (E) on southwest facing slopes and for basal area (B) in all plots, (D) on northeast facing slopes, and $(\mathrm{F})$ on southwest facing slopes. Horizontal lines in box plots indicate weighted median elevation. Numbers on $x$-axis represent sample sizes (i.e., plots in which a species was present). Species codes are as in Fig. 1.

Herbivore pressure is generally higher at low-elevation winter ranges (Baker et al. 1997, Suzuki et al. 1999). While not specifically quantified, three plots exhibited clear signs of intense herbivory in the form of considerably stunted growth of young suckers. These sites are located in Estes Valley, a prime winter range for the large elk population in Rocky Mountain National Park. Baker et al. (1997) found that aspen only regenerated in this area when there were fewer than 600 elk in the park. The current elk population in the park fluctuates between 600 and 800 in the winter (Scott Esser; personal communication). Similar to our study, Suzuki et al. (1999) and Kaye et al. (2005) found that aspen were negatively impacted by browsing at the stand level, but were resilient at the landscape scale in Rocky Mountain 
National Park and surrounding forests. Aspen age distribution in the park showed that $80-95 \%$ fewer aspen established from 1975 to 1995 at lower elevations on the east side of the park while across the rest of the park, aspen regeneration was not significantly different than expected, based on trends from 1855 through 1965 (Binkley 2008). In contrast to isolated, local impacts of herbivory, Rogers and Mittanck (2014) found landscape-wide vulnerability to collapse of aspen in the Book Cliffs region of eastern Utah and western Colorado and state herbivory as a major factor, but also noted differences in browsing behavior between seral and stable aspen communities. Complex relationships between browsing and aspen regeneration have been reported across the globe including for European aspen (Populus tremula), suggesting that management of aspen must be adjusted regionally (Edenius and Ericsson 2007). Despite signs of localized herbivory, our data do not indicate that browsing at low elevations resulted in significant decreases of aspen during the past 40 years.

Another potential driver responsible for the observed difference in sucker density between elevation zones are environmental factors. While warmer soil temperatures stimulate suckering, drought may be a limiting factor for aspen regeneration (Frey et al. 2003), especially at higher elevations where the effects of climate change are more pronounced (McGuire et al. 2012). The observed differences between aspen migration on northeast vs. southwest facing slopes further alludes to the importance of local environmental conditions (Table 3, Fig. 6).

While we did not assess potential aspen emergence by resampling plots that previously did not contain aspen, a separate resampling effort based on a subset of 68 of Peet's original plots with emphasis on subalpine spruce-fir and lodgepole pine forests showed emergence of aspen in six plots that previously did not contain aspen. Four of these plots were burned between samplings and showed rigorous seedling establishment, while two unburned plots had only one to very few individuals (Esser 2015). It is unknown whether these new individuals were of sexual or asexual origin; however, the emergence of numerous, densely clustered stems in the burned areas suggests vegetative origin in these plots (Scott Esser; personal communication). Conditions for dispersal (i.e., successful seed germination and sapling establishment) are considered extremely rare in Colorado (McDonough 1985, Zeigenfuss et al. 2008) and it has been shown that other clonal tree species predominantly reproduce asexually at the trailing edge of their distribution (Wei et al. 2015). However, recent work suggests that sexual reproduction may be more prevalent than previously thought and has been observed in the eastern Sierra Nevada, California, and in central Arizona (Fairweather et al. 2014, Krasnow and Stephens 2015). Hence, it cannot be excluded that aspen have dispersed successfully in the park.

\section{Elevational shifts}

While we must interpret the results presented here with caution since they only include stands where aspen was present, the observed, predominantly upslope shifts are consistent with observations in other studies worldwide. Lenoir et al. (2008) found a significant upward shift, averaging $29 \mathrm{~m} /$ decade, in species optimum elevation of 171 forest plant species throughout Western Europe over the past century. Kelly and Goulden (2008) reported an average upslope shift of $69 \mathrm{~m}$ over a 30 -year period in southern Californian's Santa Rosa Mountains. Parolo and Rossi (2008) found upslope migration rates of $23.9 \mathrm{~m} /$ decade based on comparison with historic records in the Rhaetian Alps, northern Italy. These studies concluded that climate change is the main driver of the observed shifts.

The overall more pronounced shifts on northeast facing slopes suggest moisture as an important factor in movement of species of the Colorado Front Range. Colorado's climate has become steadily warmer over the past century. While annual precipitation amounts show no clear trend since 1970, the Palmer Drought Severity Index suggests a gradual transition into drought conditions since the 2000s (precipitation data available online). ${ }^{4}$ Species migration along an elevational gradient can be limited by moisture availability (McCain and Colwell 2011). Typically higher levels of moisture on northeast facing slopes have the potential to increase successful establishment of seedlings, explaining the higher migration rate of species on these slopes compared to warmer, drier southwest facing slopes.

In addition to upward shifts, our data show downslope shifts of limber pine and, most notably, aspen (Fig. 6). The observed downward migration of aspen is contrary to modeling efforts in other studies that have shown higher mortality of aspen at lower elevations and resulting upward shifts (Worrall et al. 2008, 2013, Rehfeldt et al. 2009). One possible cause for a species' downslope shift can be competitive pressure from other species (Lenoir et al. 2010). Our data suggest the presence of such pressure exerted on aspen as indicated by upward shifts of the successional species Abies bifolia, Pinus contorta, and Picea engelmannii (Fig. 6). It should be noted that median elevation of aspen based on basal area shifted upward by $12.2 \mathrm{~m} /$ decade on southwest-facing slopes while a downslope shift of $-4.7 \mathrm{~m} /$ decade is evident on northeast-facing slopes (Table 3, Fig. 6). Strand et al. (2009) showed that drier, warmer conditions on south facings slopes impede conifer encroachment in high elevation aspen stands in southwestern Idaho, providing a potential explanation for the observed pattern in our data.

\section{Conclusion}

Aspen forests around the globe are of high conservation concern due to their ability to host a higher number of species compared to otherwise predominantly coniferous forests in their range (Chong et al.

\footnotetext{
${ }^{4}$ http://www.ncdc.noaa.gov/cdo-web/datasets/ANNUAL/ locations/FIPS:08/detail
} 
2001, Edenius and Ericsson 2007, Edenius et al. 2011, Kuhn et al. 2011). However, aspen forests face several threats across their range, including altered disturbance regimes due to fire suppression, increased herbivore pressure, human development, and climate change. Monitoring aspen populations through direct resampling yields valuable data to inform land managers of optimum management strategies and validate models.

Data from this study show decreasing abundance and replacement of aspen by successional species in Colorado Front Range forest communities where aspen has been the dominant species, but suggest that mature aspen in mixed and conifer-dominated forests is relatively resilient and may be a beneficiary of the mountain pine beetle outbreak. The slow replacement of aspen by conifers in the absence of fire is part of the natural succession in the forested montane and subalpine elevation zones of the Colorado Rocky Mountains, although stable aspen stands have also been reported for Colorado (Kashian et al. 2007, Kurzel et al. 2007, McCullough et al. 2013). In Rocky Mountain National Park, localized heavy herbivory at low elevations was evident, but not a major inhibitor of aspen recruitment at the landscape scale. Our results confirm findings by other studies across the globe that aspen's ability to persist in the landscape varies strongly by location and that no general, landscape-wide recommendations for management can be made (Harniss and Harper 1982, Edenius and Ericsson 2007, Kashian et al. 2007, Kurzel et al. 2007, Rogers et al. 2014).

\section{AcKNowledgments}

The authors thank Robert M. Hubbard, James P. Doerner, Mitchell McGlaughlin, Daniel Beverly, Scott Esser, Karina Puikkonen, and Robert H. Whittaker, the members of the 1972-1973 and 2012-2013 field crews, and the administrations of McGraw Ranch, McGregor Ranch, and the Estes Park Gun and Archery Club. The authors, furthermore, would like to thank two reviewers for their valuable input on earlier versions of this manuscript. Funding for this research was provided by the Colorado Native Plant Society, Colorado Mountain Club, and the College of Natural and Health Sciences at the University of Northern Colorado.

\section{Literature Cited}

Ackerfield, J. 2013. The flora of Colorado. Colorado. Botanical Research Institute of Texas, Fort Worth, Texas, USA. 818 pp.

Allen, C. D. and D. D. Breshears. 1998. Drought-induced shift of a forest-woodland ecotone: rapid landscape response to climate variation. Proceedings of the National Academy of Sciences USA 95:14839-14842.

Anderegg, W. R. 2012. Complex aspen forest carbon and root dynamics during drought. Climatic Change 111:983-991.

Anderegg, W. R. L., L. Plavcová, L. D. L. Anderegg, U. G. Hacke, J. A. Berry, and C. B. Field. 2013. Drought's legacy: multiyear hydraulic deterioration underlies widespread aspen forest die-off and portends increased future risk. Global Change Biology 19:1188-1196.

Anderegg, W. R., A. Flint, C.-y. Huang, L. Flint, J. A. Berry, F. W. Davis, J. S. Sperry and C. B. Field. 2015. Tree mortality predicted from drought-induced vascular damage. Nature Geoscience 8:367-371.

Aplet, G. H., R. D. Laven and F. W. Smith. 1988. Patterns of community dynamics in Colorado Engelmann spruce-subalpine fir forests. Ecology 69:312-319.

Baker, W. L., J. A. Munroe, and A. E. Hessl. 1997. The effects of elk on aspen in the winter range in Rocky Mountain National Park. Ecography 20:155-165.

Barnett, D., and T. Stohlgren. 2001. Aspen persistence near the National Elk Refuge and Gros Ventre Valley elk feedgrounds of Wyoming, USA. Landscape Ecology 16:569-580.

Bartos, D. L. 2001. Landscape dynamics of aspen and conifer forests. Pages 5-14 in W. D. Shepperd, D. Binkley, D. L. Bartos, T. J. Stohlgren, and L. G. Eskew, comps. Sustaining aspen in western landscapes. Symposium proceedings; 13-15 June 2000. Grand Junction, CO. Proceedings RMRS-P-18. U.S. Department of Agriculture, Forest Service, Rocky Mountain Research Station, Fort Collins, Colorado, USA.

Bartos, D. L., and R. B. Jr Campbell. 1998. Decline of quaking aspen in the interior West: examples from Utah. Rangelands 20:17-24.

Binkley, D. 2008. Age distribution of aspen in Rocky Mountain National Park, USA. Forest Ecology and Management 255:797-802.

Bretfeld, M. 2014. The effects of insect-induced competitor die-off on a pioneer, clonal tree species in Colorado: an assessment of temporal changes in Populus tremuloides distribution, physiological responses, and clonal integration. Dissertation. University of Northern Colorado, Greeley, Colorado, USA.

Bretfeld, M., J. P. Doerner, and S. B. Franklin. 2015. Radial growth response and vegetative sprouting of aspen following release from competition due to insect-induced conifer mortality. Forest Ecology and Management 347:96-106.

Brodie, J., E. Post, F. Watson, and J. Berger. 2012. Climate change intensification of herbivore impacts on tree recruitment. Proceedings of the Royal Society B 279:1366-1370.

Buck, J. R. and S. B. St. Clair. 2012. Aspen increase soil moisture, nutrients, organic matter and respiration in Rocky Mountain forest communities. PLoS ONE 7:e52369.

Buechling, A., and W. L. Baker. 2004. A fire history from tree rings in a high-elevation forest of Rocky Mountain National Park. Canadian Journal of Forest Research 34:1259-1273.

Chong, G. W., S. E. Simonson, T. J. Stohlgren and M. A. Kalkhan. 2001. Biodiversity: aspen stands have the lead, but will nonnative species take over? Pages 261-272 in W. D. Shepperd, D. Binkley, D. L. Bartos, T. J. Stohlgren, and L. G. Eskew, compilers. Sustaining aspen in western landscapes. Symposium proceedings; 13-15 June 2000. Grand Junction, CO. Proceedings RMRS-P-18. U.S. Department of Agriculture, Forest Service, Rocky Mountain Research Station, Fort Collins, Colorado, USA.

Collins, B. J., C. C. Rhoades, M. A. Battaglia, and R. M. Hubbard. 2012. The effects of bark beetle outbreaks on forest development, fuel loads and potential fire behavior in salvage logged and untreated lodgepole pine forests. Forest Ecology and Management 284:260-268.

Coop, J. D., and A. W. Schoettle. 2009. Regeneration of Rocky Mountain bristlecone pine (Pinus aristata) and limber pine (Pinus flexilis) three decades after stand-replacing fires. Forest Ecology and Management 257:893-903.

Coop, J. D., K. J. Barker, A. D. Knight, and J. S. Pecharich. 2014. Aspen (Populus tremuloides) stand dynamics and understory plant community changes over 46 years near Crested Butte, Colorado, USA. Forest Ecology and Management 318:1-12.

Crawford, J. L., S. P. McNulty, J. B. Sowell, and M. D. Morgan. 1998. Changes in aspen communities over 30 years in 
Gunnison County, Colorado. American Midland Naturalist 140:197-205.

Damschen, E. I., S. Harrison, and J. B. Grace. 2010. Climate change effects on an endemic-rich edaphic flora: resurveying Robert H. Whittaker's Siskiyou sites (Oregon, USA). Ecology 91:3609-3619.

DeRose, R. J., and J. N. Long. 2010. Regeneration response and seedling bank dynamics on a Dendroctonus rufipennis-killed Picea engelmannii landscape. Journal of Vegetation Science 21:377-387.

Di Orio, A. P., R. Callas, and R. J. Schaefer. 2005. Forty-eight year decline and fragmentation of aspen (Populus tremuloides) in the South Warner Mountains of California. Forest Ecology and Management 206:307-313.

Edenius, L., and G. Ericsson. 2007. Aspen demographics in relation to spatial context and ungulate browsing: implications for conservation and forest management. Biological Conservation 135:293-301.

Edenius, L., G. Ericsson, G. Kempe, R. Bergström, and K. Danell. 2011. The effects of changing land use and browsing on aspen abundance and regeneration: a 50-year perspective from Sweden. Journal of Applied Ecology 48:301-309.

Elliott, G. P., and W. L. Baker. 2004. Quaking aspen (Populus tremuloides Michx.) at treeline: a century of change in the San Juan Mountains, Colorado, USA. Journal of Biogeography 31:733-745.

Esser, S. 2015. Topography, disturbance and climate: subalpine forest change 1972 - 2013, Rocky Mountain National Park, USA. Thesis. Colorado State University, Fort Collins, Colorado, USA.

Evans, L., G. Allan, S. DiFazio, G. Slavov, J. Wilder, K. Floate, S. Rood, and T. Whitham. 2015. Geographical barriers and climate influence demographic history in narrowleaf cottonwoods. Heredity 114:387-396.

Fairweather, M. L., B. W. Geils and M. Manthei. 2008. Aspen decline on the Coconino National Forest. Pages 53-62 in M. McWilliams, editors. Proceedings of the 55th Western International Forest Disease Work Conference. Oregon Department of Forestry, Salem, Oregon, USA.

Fairweather, M. L., E. Rokala, and K. E. Mock. 2014. Aspen seedling establishment and growth after wildfire in central Arizona: an instructive case history. Forest Science 60:703-712.

Frey, B. R., V. J. Lieffers, S. M. Landhausser, P. G. Comeau, and K. J. Greenway. 2003. An analysis of sucker regeneration of trembling aspen. Canadian Journal of Forest Research 33:1169-1179.

Frey, B. R., V. J. Lieffers, E. Hogg, and S. M. Landhäusser. 2004. Predicting landscape patterns of aspen dieback: mechanisms and knowledge gaps. Canadian Journal of Forest Research 34:1379-1390.

Gallant, A. L., A. J. Hansen, J. S. Councilman, D. K. Monte, and D. W. Betz. 2003. Vegetation dynamics under fire exclusion and logging in a Rocky Mountain watershed, 1856-1996. Ecological Applications 13:385-403.

Hadley, K. S., and T. T. Veblen. 1993. Stand response to western spruce budworm and Douglas-fir bark beetle outbreaks, Colorado Front Range. Canadian Journal of Forest Research 23:479-491.

Harniss, R. O. and K. T. Harper. 1982. Tree dynamics in seral and stable aspen stands of central Utah. Research Paper INT297. USDA Forest Service, Ogden, Utah, USA.

Harte, J., and R. Shaw. 1995. Shifting dominance within a montane vegetation community: results of a climate-warming experiment. Science 267:876-880.

Hess, K. and R. R. Alexander. 1986. Forest vegetation of the Arapaho and Roosevelt National Forests in central Colorado: a habitat type classification. Research paper RM 266. U.S.
Department of Agriculture, Forest Service, Rocky Mountain Forest and Range Experiment Station, Fort Collins, Colorado, USA.

Hessl, A. E., and L. J. Graumlich. 2002. Interactive effects of human activities, herbivory and fire on quaking aspen (Populus tremuloides) age structures in western Wyoming. Journal of Biogeography 29:889-902.

IPCC. 2013. Climate change 2013: the physical science basis. Cambridge University Press, Cambridge, UK and New York, New York, USA.

Jagerbrand, A. K., J. M. Alatalo, D. Chrimes, and U. Molau. 2009. Plant community responses to 5 years of simulated climate change in meadow and heath ecosystems at a subarctic-alpine site. Oecologia 161:601-610.

Jenkins, M. J., E. Hebertson, W. Page, and C. A. Jorgensen. 2008. Bark beetles, fuels, fires and implications for forest management in the Intermountain West. Forest Ecology and Management 254:16-34.

Jenkins, M. J., W. G. Page, E. G. Hebertson, and M. E. Alexander. 2012. Fuels and fire behavior dynamics in bark beetle-attacked forests in Western North America and implications for fire management. Forest Ecology and Management 275:23-34.

Jones, B. E., T. H. Rickman, A. Vazquez, Y. Sado, and K. W. Tate. 2005. Removal of encroaching conifers to regenerate degraded aspen stands in the Sierra Nevada. Restoration Ecology 13:373-379.

Kashian, D. M., W. H. Romme, and C. M. Regan. 2007. Reconciling divergent interpretations of quaking aspen decline on the northern Colorado Front Range. Ecological Applications 17:1296-1311.

Kay, C. E. 1993. Aspen seedlings in recently burned areas of Grand Teton and Yellowstone National Parks. Northwest Science 67:94-104.

Kaye, M. W., D. Binkley, and T. J. Stohlgren. 2005. Effects of conifers and elk browsing on quaking aspen forests in the central Rocky Mountains, USA. Ecological Applications 15:1284-1295.

Kearns, H. S., and W. R. Jacobi. 2007. The distribution and incidence of white pine blister rust in central and southeastern Wyoming and northern Colorado. Canadian Journal of Forest Research 37:462-472.

Kelly, A. E. and M. L. Goulden. 2008. Rapid shifts in plant distribution with recent climate change. Proceedings of the National Academy of Sciences USA 105:11823-11826.

Klutsch, J. G., J. F. Negrón, S. L. Costello, C. C. Rhoades, D. R. West, J. Popp, and R. Caissie. 2009. Stand characteristics and downed woody debris accumulations associated with a mountain pine beetle (Dendroctonus ponderosae Hopkins) outbreak in Colorado. Forest Ecology and Management 258:641-649.

Kopecký, M., and M. Macek. 2015. Vegetation resurvey is robust to plot location uncertainty. Diversity and Distributions 21:322-330.

Kopp, C. W., and E. E. Cleland. 2014. Shifts in plant species elevational range limits and abundances observed over nearly five decades in a western North America mountain range. Journal of Vegetation Science 25:135-146.

Kouki, J., K. Arnold, and P. Martikainen. 2004. Long-term persistence of aspen - a key host for many threatened speciesis endangered in old-growth conservation areas in Finland. Journal for Nature Conservation 12:41-52.

Krasnow, K. D. and S. L. Stephens. 2015. Evolving paradigms of aspen ecology and management: impacts of stand condition and fire severity on vegetation dynamics. Ecosphere 6:art12.

Krebill, R. G. 1972. Mortality of aspen on the Gros Ventre elk winter range. USDA Forest Service Intermountain Forest and Range Experiment Station. Research Paper INT-129. 
Kuhn, T. J., H. D. Safford, B. E. Jones, and K. W. Tate. 2011. Aspen (Populus tremuloides) stands and their contribution to plant diversity in a semiarid coniferous landscape. Plant Ecology 212:1451-1463.

Kulakowski, D., T. T. Veblen, and S. Drinkwater. 2004. The persistence of quaking aspen (Populus tremuloides) in the Grand Mesa Area, Colorado. Ecological Applications 14:1603-1614.

Kulakowski, D., T. T. Veblen, and B. P. Kurzel. 2006. Influences of infrequent fire, elevation and pre-fire vegetation on the persistence of quaking aspen (Populus tremuloides Michx.) in the Flat Tops area, Colorado, USA. Journal of Biogeography 33:1397-1413.

Kurzel, B. P., T. T. Veblen, and D. Kulakowski. 2007. A typology of stand structure and dynamics of quaking aspen in northwestern Colorado. Forest Ecology and Management 252:176-190.

Lenoir, J., J. C. Gegout, P. A. Marquet, P. de Ruffray, and H. Brisse. 2008. A significant upward shift in plant species optimum elevation during the 20th century. Science 320:1768-1771.

Lenoir, J., J.-C. Gégout, A. Guisan, P. Vittoz, T. Wohlgemuth, N. E. Zimmermann, S. Dullinger, H. Pauli, W. Willner, and J.-C. Svenning. 2010. Going against the flow: potential mechanisms for unexpected downslope range shifts in a warming climate. Ecography 33:295-303.

Lieffers, V. J., B. D. Pinno, and K. J. Stadt. 2002. Light dynamics and free-to-grow standards in aspen-dominated mixedwood forests. Forestry Chronicle 78:137-145.

Littell, J. S., D. McKenzie, D. L. Peterson, and A. L. Westerling. 2009. Climate and wildfire area burned in western U.S. ecoprovinces, 1916-2003. Ecological Applications 19:1003-1021.

Little, E. L. Jr. 1971. Atlas of the United States Trees, Conifers and Important Hardwoods, Volume 1. US Department of Agriculture Miscellaneous Publication No. 1146, Washington, D.C.

Long, J. N., and K. Mock. 2012. Changing perspectives on regeneration ecology and genetic diversity in western quaking aspen: implications for silviculture. Canadian Journal of Forest Research 42:2011-2021.

Lynch, H. J., R. A. Renkin, R. L. Crabtree, and P. R. Moorcroft. 2007. The influence of previous mountain pine beetle (Dendroctonus ponderosae) activity on the 1988 Yellowstone fires. Ecosystems 9:1318-1327.

Malanson, G. P., L. M. Resler, M. Y. Bader, F.-K. Holtmeier, D. R. Butler, D. J. Weiss, L. D. Daniels, and D. B. Fagre. 2011. Mountain treelines: a roadmap for research orientation. Arctic, Antarctic, and Alpine Research 43:167-177.

Manier, D. J., and R. D. Laven. 2002. Changes in landscape patterns associated with the persistence of aspen (Populus tremuloides Michx.) on the western slope of the Rocky Mountains Colorado. Forest Ecology and Management 167:263-284.

McCain, C. M., and R. K. Colwell. 2011. Assessing the threat to montane biodiversity from discordant shifts in temperature and precipitation in a changing climate. Ecology Letters 14:1236-1245.

McCullough, S. A., A. T. O'Geen, M. L. Whiting, D. A. Sarr, and K. W. Tate. 2013. Quantifying the consequences of conifer succession in aspen stands: decline in a biodiversitysupporting community. Environmental Monitoring and Assessment 185:5563-5576.

McCune, B. and M. J. Mefford. 2011. PC-ORD. Multivariate Analysis of Ecological Data. Version 6. MjM Software, Gleneden Beach, Oregon, USA.

McDonough, W. T. 1985. Sexual reproduction, seeds, and seedlings. Pages 25-28 in Aspen: ecology and management in the western United States. General Technical Report RM-119. US Department of Agriculture, Forest Service, Rocky Mountain Forest and Range Experiment Station, Fort Collins, Colorado, USA.
McGuire, C. R., C. R. Nufio, M. D. Bowers, and R. P. Guralnick. 2012. Elevation-dependent temperature trends in the Rocky Mountain Front Range: changes over a 56- and 20-year record. PLoS ONE 7:e44370.

Michaelian, M., E. H. Hogg, R. J. Hall, and E. Arsenault. 2011. Massive mortality of aspen following severe drought along the southern edge of the Canadian boreal forest. Global Change Biology 17:2084-2094.

Mitton, J. B., and M. C. Grant. 1996. Genetic variation and the natural history of quaking aspen. BioScience 46:25-31.

Moore, M., and D. Huffman. 2004. Tree encroachment on meadows of the North Rim, Grand Canyon National Park, Arizona, U.S.A. Arctic, Antarctic, and Alpine Research 36:474 483.

Packard, F. M. 1942. Wildlife and aspen in Rocky Mountain National Park, Colorado. Ecology 23:478-482.

Parolo, G., and G. Rossi. 2008. Upward migration of vascular plants following a climate warming trend in the Alps. Basic and Applied Ecology 9:100-107.

Peet, R. K. 1981. Forest vegetation of the Colorado front range. Plant Ecology 45:3-75.

Peet, R. K., T. R. Wentworth, and P. S. White. 1998. A flexible, multipurpose method for recording vegetation composition and structure. Castanea 63:262-274.

Pelz, K. A., and F. W. Smith. 2013. How will aspen respond to mountain pine beetle? A review of literature and discussion of knowledge gaps. Forest Ecology and Management 299:60-69.

Pike, N. 2011. Using false discovery rates for multiple comparisons in ecology and evolution. Methods in Ecology and Evolution 2:278-282.

R Development Core Team. 2008. R: a language and environment for statistics computing. R Foundation for Statistical Computing, Vienna, Austria. ISBN 3-900051-07-0, http:// www.R-project.org

Rebertus, A. J., B. R. Burns, and T. T. Veblen. 1991. Stand dynamics of Pinus flexilis-dominated subalpine forests in the Colorado Front Range. Journal of Vegetation Science 2:445-458.

Rehfeldt, G. E., D. E. Ferguson, and N. L. Crookston. 2009. Aspen, climate, and sudden decline in western USA. Forest Ecology and Management 258:2353-2364.

Ripple, W. J., and E. J. Larsen. 2000. Historic aspen recruitment, elk, and wolves in northern Yellowstone National Park, USA. Biological Conservation 95:361-370.

Rogers, P. C., and C. M. Mittanck. 2014. Herbivory strains resilience in drought-prone aspen landscapes of the western United States. Journal of Vegetation Science 25:457-469.

Rogers, P. C., C. Eisenberg and S. B. St. Clair. 2013. Resilience in quaking aspen: recent advances and future needs. Forest Ecology and Management 299:1-5.

Rogers, P. C., S. M. Landhäusser, B. D. Pinno, and R. J. Ryel. 2014. A functional framework for improved management of western North American aspen (Populus tremuloides Michx.). Forest Science 60:345-359.

Romme, W. H., M. G. Turner, L. L. Wallace, and J. S. Walker. 1995. Aspen, elk, and fire in northern Yellowstone Park. Ecology 76:2097-2106.

Romme, W. H., M. G. Turner, G. A. Tuskan, and R. A. Reed. 2005. Establishment, persistence, and growth of aspen (Populus tremuloides) seedlings in Yellowstone National Park. Ecology 86:404-418.

Sankey, T. T. 2008. Learning from spatial variability: aspen persistence in the Centennial Valley, Montana. Forest Ecology and Management 255:1219-1225.

Sankey, T. T. 2012. Decadal-scale aspen changes: evidence in remote sensing and tree ring data. Applied Vegetation Science 15:84-98. 
Seager, S. T., C. Eisenberg and S. B. St. Clair. 2013. Patterns and consequences of ungulate herbivory on aspen in western North America. Forest Ecology and Management 299:81-90.

Shaw, J. D. 2005. Aspen stand structure and composition in the western U.S.: Implications for Management. In Proceedings: Canadian Institute of Forestry / Society of American Foresters Joint 2004 Annual General Meeting and Convention. October 2-6, 2004. Edmonton, Alberta, Canada. Bethesda, Maryland: Society of American Foresters. [published on CD-ROM].

Shepperd, W. D., P. C. Rogers, D. Burton and D. L. Bartos. 2006. Ecology, biodiversity, management, and restoration of aspen in the Sierra Nevada. General Technical Report RMRS-GTR-178. U.S. Department of Agriculture, Forest Service, Rocky Mountain Research Station, Fort Collins, Colorado, USA .

Sibold, J. S., T. T. Veblen, and M. E. González. 2006. Spatial and temporal variation in historic fire regimes in subalpine forests across the Colorado Front Range in Rocky Mountain National Park, Colorado, USA. Journal of Biogeography 33:631-647.

Smith, A. E., and F. W. Smith. 2005. Twenty-year change in aspen dominance in pure aspen and mixed aspen/conifer stands on the Uncompahgre Plateau, Colorado, USA. Forest Ecology and Management 213:338-348.

St. Clair, S. B., J. Guyon, and J. Donaldson. 2010. Quaking aspen's current and future status in western North America: the role of succession, climate, biotic agents and its clonal nature. Pages 371-400 in U. Lüttge, W. Beyschlag, B. Büdel and D. Francis, editors. Progress in Botany 71. Springer, Berlin, Germany.

Stam, B. R., J. C. Malechek, D. L. Bartos, J. E. Bowns, and E. B. Godfrey. 2008. Effect of conifer encroachment into aspen stands on understory biomass. Rangeland Ecology \& Management 61:93-97. U.S. Geological Survey Open-File Rep. 2008-1337. U.S. Geological Survey, Reston, VA.

Strand, E. K., L. A. Vierling, S. C. Bunting, and P. E. Gessler. 2009. Quantifying successional rates in western aspen woodlands: current conditions, future predictions. Forest Ecology and Management 257:1705-1715.

Suzuki, K., H. Suzuki, D. Binkley, and T. Stohlgren. 1999. Aspen regeneration in the Colorado Front Range: differences at local and landscape scales. Landscape Ecology 14:231-237.
Thuiller, W., S. Lavorel, M. B. Araújo, M. T. Sykes, and I. C. Prentice. 2005. Climate change threats to plant diversity in Europe. Proceedings of the National Academy of Sciences USA 102:8245-8250.

Veblen, T. T., T. Kitzberger, and J. Donnegan. 2000. Climatic and human influences on fire regimes in Ponderosa pine forests in the Colorado Front Range. Ecological Applications 10:1178-1195.

Wei, X., H. Wu, H. Meng, C. Pang, and M. Jiang. 2015. Regeneration dynamics of Euptelea pleiospermum along latitudinal and altitudinal gradients: trade-offs between seedling and sprout. Forest Ecology and Management 353:232-239.

Westerling, A. L., H. G. Hidalgo, D. R. Cayan, and T. W. Swetnam. 2006. Warming and earlier spring increase western U.S. forest wildfire activity. Science 313:940-943.

Westoby, M. 1984. The self-thinning rule. Advances in Ecological Research 14:167-226.

Whittaker, R. H. 1960. Vegetation of the Siskiyou Mountains, Oregon and California. Ecological Monographs 30:279-338.

Whittaker, R. H. 1967. Gradient analysis of vegetation. Biological Reviews 42:207-264.

Williams, J. W., and S. T. Jackson. 2007. Novel climates, noanalog communities, and ecological surprises. Frontiers in Ecology and the Environment 5:475-482.

Woodall, C., C. Oswalt, J. Westfall, C. Perry, M. Nelson, and A. Finley. 2009. An indicator of tree migration in forests of the eastern United States. Forest Ecology and Management 257:1434-1444.

Worrall, J. J., L. Egeland, T. Eager, R. A. Mask, E. W. Johnson, P. A. Kemp, and W. D. Shepperd. 2008. Rapid mortality of Populus tremuloides in southwestern Colorado, USA. Forest Ecology and Management 255:686-696.

Worrall, J. J., G. E. Rehfeldt, A. Hamann, E. H. Hogg, S. B. Marchetti, M. Michaelian, and L. K. Gray. 2013. Recent declines of Populus tremuloides in North America linked to climate. Forest Ecology and Management 299:35-51.

Zeigenfuss, L. C., D. Binkley, G. A. Tuskan, W. H. Romme, T. Yin, S. DiFazio and F. J. Singer. 2008. Aspen ecology in Rocky Mountain National Park: Age distribution, genetics, and the effects of elk herbivory. Open-File Report 2008-1337.

Zier, J. L., and W. L. Baker. 2006. A century of vegetation change in the San Juan Mountains, Colorado: an analysis using repeat photography. Forest Ecology and Management 228:251-262.

\section{SUPPORTING INFORMATION}

Additional supporting information may be found in the online version of this article at http://onlinelibrary.wiley.com/ doi/10.1890/15-1195.1/suppinfo

\section{Data Availability}

Data associated with this paper have been deposited in DANS: http://dx.doi.org/10.17026/dans-xd8-37qq 